\title{
Barriers of Appropriate Complementary Feeding Practices in Under - 2 Children
}

\author{
SK PAUL ${ }^{\mathrm{a}}$, S ROY ${ }^{\mathrm{b}}$, QR ISLAM ${ }^{\mathrm{c}}$, MZ ISLAM ${ }^{\mathrm{d}}$, M AKTERUZZAMAN ${ }^{\mathrm{e}}$, \\ MAROUF ${ }^{\mathrm{f}}$, ARML KABIR', S AFROZA ${ }^{\mathrm{h}}$
}

\begin{abstract}
Summary:
When breast milk is no longer enough to meet the nutritional needs of infants, complementary foods should be added to their diet. It is a very vulnerable period when malnutrition starts in many infants, contributing significantly to high prevalence of malnutrition in under-5 children world-wide. In Bangladesh, complementary feeding (CF) practices are not satisfactory. The objectives of the study were to look into the feeding patterns of under-2 children and to identify the causes which lead mothers/ caregivers to practice inappropriate CF. This cross-sectional study was done in the Pediatric department of Sir Salimullah Medical College Mitford Hospital, Dhaka and in a private chamber from a district town of Bangladesh from October, 2011 to December, 2011. Four hundred mother-child pairs were enrolled by non-random convenience sampling. Different aspects of feeding practices (age of initiation of CF, type of first
\end{abstract}

Introduction:

When breast milk is no longer enough to meet the nutritional needs of the infant, complementary foods should be added to the diet of the child. The transition

a. Dr. Shanjoy Kumar Paul, Associate Professor (Pediatric Nephrology), Sir Salimullah Medical College (SSMC).

b. Dr. Sunirmal Roy, Associate Professor (Neonatology), SSMC.

c. Dr. Quazi Rakibul Islam, Associate Professor (Pediatrics),Green life Medical College, Dhaka.

d. Dr. Md. Zakirul Islam, Assistant Professor (Pediatrics), SSMC.

e. Dr. Md. Akteruzzaman, Junior Consultant (Pediatrics), Upazilla Health Complex, Kachua, Chandpur.

f. Dr. Md. Abdur Rouf, Associate Professor (Pediatrics), SSMC.

g. Prof. ARM Luthful Kabir, Professor (Pediatrics), SSMC.

h. Prof. Syeda Afroza, Professor (Pediatrics), Shahid Suhrawardy Medical College, Dhaka, Bangladesh

Address of Correspondence: Dr. Shanjoy Kumar Paul, Associate Professor (Pediatric Nephrology), Sir Salimullah Medical College, Dhaka, Bangladesh. Mobile phone no. 01716330978. Email: drshanjoy@gmail.com, shanjoykumarpaul @ yahoo.com.au

Accepted: 4 March, 2014

Accepted: 25 August, 2015 complementary food, current main complementary food \& its quantity, and frequency of $\mathrm{CF}$ ) were analyzed. Bottle feeding, fast foods and lack of proper family support were most important barriers $(p<0.05)$. High rate of early initiation of CF was mainly due to mothers' perception that breast milk alone was not enough (81.8\%) and main cause of late initiation was refusal of complementary foods by their babies (48.4\%). Feeding practices were mainly influenced by relatives (25\%), qualified doctors (15.3\%), neighbors (14.5\%) \& mother-in-laws (13.5\%). CF practices are still far from ideal. Strengthening of nutrition education to mothers/caregivers and family members/relatives along with awareness building in the community may change the wrong practices.

Key words: Barriers, Complementary feeding

(J Banagladesh Coll Phys Surg 2015; 33: 195-201)

from exclusive breast feeding to family foods, referred to as complementary feeding (CF), typically covers the period from 6 to 18-24 months of age, and is a very vulnerable period. It is the time when malnutrition starts in many infants, contributing significantly to the high prevalence of malnutrition in children less than five years of age world-wide ${ }^{1,2,3,4,5}$. World Health Organization estimates that two out of five children are stunted in low-income countries ${ }^{1}$. Poor feeding practices and low quality foods can affect future learning ability, economic productivity, immune response and reproductive outcomes ${ }^{6}$. Cultural factors and taboos appeared to have an important influence on mothers' infant-feeding practices and eating patterns of their children ${ }^{7}$. In Bangladesh, CF practices are not satisfactory. A recent study in a medical college of Dhaka city showed that amount, composition \& consistency of complementary foods are not optimal ${ }^{8}$. Another study in a rural area of Dhaka district also found that onset, type and frequency of CF are not acceptable ${ }^{9}$. Similar findings were observed by other investigators in urban slum, semiurban \& rural areas of our country $10,11,12$.

The objectives of the study were to look into the feeding patterns of under-2 children including age of initiation 
of CF \& its frequency, type of first complementary foods, composition \& quantity of complementary foods, and to identify the causes which lead mothers/ caregivers of children to practice inappropriate CF.

\section{Methods:}

A cross-sectional study was conducted in the in-patient and out-patient Departments of Pediatrics, Sir Salimullah Medical College \& Mitford Hospital (SSMC\&MH), Dhaka, Bangladesh and in a private chamber at a district town (Gazipur) of Bangladesh from October, 2011 to December, 2011. A total of 400 mother-child pairs were enrolled by non- random convenience sampling. Data was collected from the mothers/caregivers of the children in a pretested semistructured questionnaire which took about 20-30 minutes in each case. Children of 6-24 months of age and children under six months (if CF was already started) were included. Children under six months (if on exclusive breast feeding) and children having major illness interfering with feeding like cerebral palsy, congenital heart disease, cleft palate etc. were excluded.

\section{Case definitions:}

Barrier - A circumstance or obstacle that keeps people or things apart or prevents communication or progress.

Characteristics of proper CF - A proper CF consists of foods that are rich in energy

and in micronutrients (especially iron, zinc, calcium, vitamin A, vitamin C and folates), free of contamination (pathogens, toxins or harmful chemicals), without much salt or spices, easy to eat and easily accepted by the infant, in an appropriate amount, easy to prepare from family foods, and at a cost that is acceptable by most families ${ }^{13}$.

Appropriate complementary foods - Khichuri, Mixed family foods (Rice, pulses, vegetables, meat, egg and fish), Bread, Pitha, Fruits, Locally processed complementary foods etc.

Inappropriate complementary foods - Rice gruel, Rice gruel with Sugar, Rice gruel with Milk, suji (Wheat), Suji with Milk, Suji with Sugar, Sago, Burly, Sugar water, Animal milk, Formula, Commercial cereal, Fast foods etc.

Khichuri - A dish prepared by mixing rice, lentils, oil, vegetables, egg/meat/fish etc.

Fast foods - Foods that are prepared and served very quickly, first popularized in the 1950s in the United
States. While any meal with low preparation time can be considered fast food, typically the term refers to food sold in a restaurant or store with preheated or precooked ingredients, and served to the customer in a packaged form for take-out/take-away. Fast food restaurants are traditionally separated by their ability to serve food via a drive-through (Wikipedia) e.g. Burger, Sandwich, French fries, Pizza, Hot dog, Noodles, Fried chicken, Chips, Biscuits, Soft drinks, Commercial juices etc. Frequency of CF was defined according to recommendation of Integrated Management of Childhood Illness (IMCI) by WHO/UNICEF.

Quantity of complementary foods was defined according to IYCF recommendation.

Knowledge about CF was assessed by asking about optimum initiation time, types of recommended complementary foods, frequency and quantity.

Data analysis: Data were analyzed by SPSS version 12 . Bivariate tables were prepared. Chi square tests were done where applicable. Statistical significance was considered to be at the level of $\mathrm{p}<0.05$.

Ethical consideration: Verbal consent was taken from the mothers/caregivers of the children after discussion about the study. Confidentiality was strictly protected. Permission was taken from the ethical committee of SSMCMH, Dhaka, Bangladesh.

\section{Results:}

Most of the children under study were from out-patient department (68.7\%) followed by private chamber (25\%) and indoor (6.3\%). 56.2\% children came from urban areas followed by rural (28.2\%), semi-urban (15.2\%) and urbanslum areas (0.2\%). Male female ratio was $1.3: 1$. Three hundred \& eighty five mothers (96.2\%) were caregivers.

Table-I

\begin{tabular}{|c|c|c|}
\hline \multicolumn{3}{|c|}{$\begin{array}{l}\text { Age (month) of initiation of complementary } \\
\text { feeding }(n=400)\end{array}$} \\
\hline Age & Frequency & Percentage \\
\hline$\leq 4$ & 60 & 15.0 \\
\hline $5-6$ & 137 & 34.2 \\
\hline 7 & 137 & 34.2 \\
\hline $8-10$ & 36 & 9.0 \\
\hline $11-12$ & 9 & 2.2 \\
\hline $13-24$ & 5 & 1.2 \\
\hline Not yet started & 16 & 4.0 \\
\hline
\end{tabular}


In 377 cases (94.2\%), mothers were housewife followed by handicraft worker in eight (2\%), service in six (1.5\%).

Mother's educational status was secondary incomplete in 185 cases (46.2\%) followed by secondary complete or higher in 81 (20.2\%), primary incomplete in 62 (15.5\%), no education in 49 (12.2\%) and primary complete in 23(5.8\%).

\section{Table-II}

\section{Reasons for early initiation of complementary} feeding $(n=121)$

\begin{tabular}{lcc} 
Reasons & Frequency & Percentage \\
\hline $\begin{array}{l}\text { Didn't get enough } \\
\text { breast milk }\end{array}$ & 99 & 81.8 \\
$\begin{array}{l}\text { Advised by elderly } \\
\text { members of family }\end{array}$ & 10 & 8.3 \\
$\begin{array}{l}\text { Did not know the time } \\
\text { of initiation of complementary } \\
\text { feeding }\end{array}$ & 5 & 4.1 \\
\begin{tabular}{l} 
Others \\
\hline
\end{tabular} & 7 & 5.8 \\
\hline
\end{tabular}

Father's educational status was secondary incomplete in 147 cases (36.8\%) followed by secondary complete or higher in 101 (25.2\%), primary incomplete in 70 (17.5\%), no education in 56 (14\%) and primary complete in 26 (6.5\%). Father's education had no significant influence on initiation, type of first complementary food and current main complementary food ( $\mathrm{p}>0.05$ ), but had significant influence on frequency of CF $(p=0.007)$.

Sixty eight percent $(n=272)$ families were single. Family status (single or joint) had no significant influence on initiation, type of first complementary food and on frequency of CF ( $>>0.05$ ) but had significant influence on current main complementary food ( $\mathrm{p}<0.05)$.

Family members were 5-10 in 207 cases (51.8\%) followed by $\leq 4$ in 177 (44.2\%) and $\geq 11$ in 16 (4\%). Family size had significant influence on current main complementary food ( $\mathrm{p}=0.045$ ), but insignificant influence on initiation, type of first complementary food and frequency of CF $(\mathrm{p}>0.05)$.

Most children (90.8\%) were from Muslim families followed by Hindu (9.2\%). Religion had no significant influence on initiation, type of first complementary food, current main complementary food and frequency of CF ( $>0.05)$.
Cultural barriers had no significant influence on initiation, type of first complementary food, current main complementary food and frequency of CF ( $>>0.05)$.

Exclusive breast-feeding for six months was only in 39 cases (9.8\%). Most children (54.1\%, n=216) were exclusively breast-fed for one month only. Most children (83.8\%, n=335) were on partial breast-feeding and 65 (16.2\%) were without breast-feeding during the time of interview.

Two hundred \& eighty three children (70.8\%) were on formula feeding, majority $(19 \%, \mathrm{n}=76)$ started within first month of life followed by 45 (11.2\%) at seventh month. It had significant influence on type of first complementary food $(\mathrm{p}=0.007)$ and current main complementary food $(\mathrm{p}=0.002)$ but had no significant influence on initiation $(\mathrm{p}=0.926)$ and frequency of $\mathrm{CF}$ $(p=0.064)$.

Table-III

Reasons for late initiation of complementary feeding $(n=62)$

\begin{tabular}{|c|c|c|}
\hline Reasons & Frequency & $\begin{array}{c}\text { Valid } \\
\text { Percent }\end{array}$ \\
\hline Got enough breast milk & 8 & 12.9 \\
\hline $\begin{array}{l}\text { Advised by elderly members } \\
\text { of family }\end{array}$ & 8 & 12.9 \\
\hline $\begin{array}{l}\text { Did not know the time of } \\
\text { initiation of complementary } \\
\text { feeding }\end{array}$ & 11 & 17.7 \\
\hline $\begin{array}{l}\text { Baby refused to take } \\
\text { complementary foods }\end{array}$ & 30 & 48.4 \\
\hline $\begin{array}{l}\text { Complementary foods } \\
\text { caused diarrhea }\end{array}$ & 3 & 4.8 \\
\hline Others & 2 & 3.2 \\
\hline
\end{tabular}

Animal milk (cow/goat) was given to 228 children (57\%), majority $(14.8 \%, n=59)$ at seventh month followed by $31(7.8 \%)$ at sixth month. It had significant influence on type of first complementary food $(p=0.05)$ but had no significant influence on initiation $(\mathrm{p}=0.973)$, current main complementary food $(p=0.996)$ and frequency of CF ( $\mathrm{p}=0.213)$.

Bottle feeding was practiced in 297 children (74.2\%), majority (19\%, n=75) at first month of life followed by 42 
(10.5\%) at seventh month, 36 (9\%) at second month and $34(8.5 \%)$ at sixth month.

Commercial cereal was given to 128 children (32\%).

Fast foods were given to 206 children (54.8\%).

Current feeding practices were mainly influenced by relatives $(25 \%, \mathrm{n}=100)$ followed by doctors $(15.3 \%$, $\mathrm{n}=61)$, neighbors (14.5\%, $\mathrm{n}=58)$, mother-in-laws $(13.5 \%$, $n=54)$, husbands $(6.3 \%, n=25)$, television $(6 \%, n=24)$, other family members $(5 \%, n=20)$ etc.

Two hundred \& ninety six mothers/caregivers (75.3\%) did not get proper support from families for CF.

Three hundred \& eighty nine mothers/caregivers (97.2\%) knew something about CF, seven knew nothing (1.8\%) and four knew well (1\%).

Attitude of mothers/caregivers towards CF was positive in 333 cases $(84.7 \%)$.
Two hundred \& fifteen mothers/caregivers (53.9\%) were given nutrition education by health workers. Nutrition education had significant influence on the type of first complementary food ( $p=0.003)$, but not on the initiation $(p=0.463)$, current main complementary food $(p=0.140)$ and frequency of $\mathrm{CF}(\mathrm{p}=0.272)$.

First complementary food was rice gruel with milk in 102 children (26.6\%) followed by khichuri in 71 (18.5\%), commercial cereal in 58 (15.1\%), rice gruel alone in 37 (9.6\%), mixed family foods in 26 (6.8\%) etc.

Current main complementary food was rice gruel with milk in 98 children (25.5\%) followed by mixed family foods in 83 (21.6\%), khichuri in 62 (16.1\%), suji (wheat) with milk in 54 (14.1\%) etc.

Regarding quantity of complementary foods per feed, 36\% were inappropriate in seventh month, 95\% in eighth month, $100 \%$ in $9-11$ th months and $97.4 \%$ in 12 th 24th months age group.

\section{Table-IV}

\begin{tabular}{|c|c|c|c|c|}
\hline \multicolumn{5}{|c|}{ Effect of bottle feeding on complementary feeding practices } \\
\hline Effect on & Yes & No & Total & $P$ value \\
\hline Initiation:Appropriate & $129(44.9 \%)$ & $58(59.8 \%)$ & $187(48.7 \%)$ & 0.011 \\
\hline Not appropriate & $158(55.1 \%)$ & $39(40.2 \%)$ & $197(51.3 \%)$ & \\
\hline Type of first complementary food:Appropriate & $65(22 \%)$ & $43(42.2 \%)$ & $108(27.1 \%)$ & 0.000 \\
\hline Not appropriate & $231(78 \%)$ & $59(57.8 \%)$ & $290(72.9 \%)$ & \\
\hline Main complementary food:Appropriate & $104(35 \%)$ & $52(51.5 \%)$ & $156(39.2 \%)$ & 0.003 \\
\hline Not appropriate & $193(65 \%)$ & $49(48.5 \%)$ & $242(60.8 \%)$ & \\
\hline Frequency of CF:Appropriate & $166(58 \%)$ & $47(50.5 \%)$ & $213(56.2 \%)$ & 0.205 \\
\hline Not appropriate & $120(42 \%)$ & $46(49.5 \%)$ & $166(43.8 \%)$ & \\
\hline
\end{tabular}

\section{Table-V}

Effect of fast foods on complementary feeding practices

\begin{tabular}{lcccc} 
Effect on & Yes & No & Total & P value \\
\hline Initiation:Appropriate & $113(54.3 \%)$ & $72(41.4 \%)$ & $185(48.4 \%)$ & 0.090 \\
Not appropriate & $95(45.7 \%)$ & $102(58.6 \%)$ & $197(51.6 \%)$ & 0.011 \\
Type of first complementary food:Appropriate & $69(32.5 \%)$ & $39(21.2 \%)$ & $108(27.3 \%)$ & $288(72.7 \%)$ \\
Not appropriate & $143(67.5 \%)$ & $145(78.8 \%)$ & $156(39.4 \%)$ & 0.000 \\
Main complementary food:Appropriate & $103(48.6 \%)$ & $53(28.8 \%)$ & $240(60.6 \%)$ & 0.000 \\
Not appropriate & $109(51.4 \%)$ & $131(71.2 \%)$ & $211(56 \%)$ & $166(44 \%)$ \\
Frequency of CF:Appropriate & $87(42.2 \%)$ & $124(72.5 \%)$ & $47(27.5 \%)$ & \\
Not appropriate & $119(57.8 \%)$ & & & \\
\hline
\end{tabular}


Table-VI

\begin{tabular}{lcccc}
\multicolumn{5}{c}{ Effect of family support on complementary feeding practices } \\
Effect on & Yes & No & Total & P value \\
\hline Initiation:Appropriate & $55(60.4 \%)$ & $126(44.1 \%)$ & $181(48 \%)$ & 0.006 \\
Not appropriate & $36(39.6 \%)$ & $160(55.9 \%)$ & $196(52 \%)$ & \\
Type of first complementary food:Appropriate & $47(48.5 \%)$ & $60(20.4 \%)$ & $107(27.4 \%)$ & 0.000 \\
Not appropriate & $50(51.5 \%)$ & $234(79.6 \%)$ & $284(72.6 \%)$ & \\
Main complementary food:Appropriate & $71(73.2 \%)$ & $82(27.9 \%)$ & $153(39.1 \%)$ & 0.000 \\
Not appropriate & $26(26.8 \%)$ & $212(72.1 \%)$ & $238(60.9 \%)$ & \\
Frequency of CF:Appropriate & $31(33.3 \%)$ & $179(64.2 \%)$ & $210(56.5 \%)$ & 0.205 \\
Not appropriate & $62(66.7 \%)$ & $100(35.8 \%)$ & $162(43.5 \%)$ & \\
\hline
\end{tabular}

Frequency of CF was inappropriate in 29 children (61.7\%) whose mothers had no education, 12 (57.1\%) with primary completed mothers, 29 (50.9\%) with primary incomplete mothers, $40.6 \%$ with secondary incomplete mothers and 25 (31.6\%) whose mothers had completed secondary education or higher. This was 31 (58.5\%), ten (45.5\%), 37 (56.9\%), 51 (35.7\%) and 37 (38.5\%) respectively in relation to father's education.

Breastfed children under one year of age were given less frequent CF (d"2 times) in 40 cases (20.2\%). But in non- breastfed children under one year of age, all were given five times or more. In children who were older than one year, frequency of CF was appropriate (e"5 times according to IMCI protocol) in only 38 (23.5\%).

Frequency of CF was inappropriate in 90 (46.6\%), 50 (42.4\%), 22 (4.5\%), four (30.8\%) and $0 \%$ of children with birth order one, two, three, four and five respectively.

\section{Discussion:}

CF practices are influenced by many factors and a bit complicated for mothers/caregivers. In this study, different aspects of CF (age of initiation, type of first complementary food, current main complementary food \& its quantity, and frequency of CF) were found to be affected by academic education of parents, pre-lacteal feeding, bottle feeding, formula feeding, commercial cereal, fast foods, feeding during sleep, family support, nutrition education, mother/caregiver's attitude towards $\mathrm{CF}$. Recall biasness and unequal sample size from urban $\&$ rural areas were main limitations of our study.

Early initiation (< six months) was still high (49.2\%). The main cause was mother's perception that the baby did not get enough breast milk, and so hungry that she was compelled to start CF. This correlates with studies done by Heinig et al. ${ }^{4}$, Lindsay ${ }^{7}$, Kumudha ${ }^{14}$, Ruel ${ }^{15}$, Giashuddin ${ }^{16}$ and Zulkifli ${ }^{17}$.

Late initiation of CF was low in this study (16.4\%). This was mainly due to baby's refusal of complementary foods. Late initiation is an important problem in different countries ${ }^{14,18,19}$. In India, religious factor in Hindu families is responsible for late initiation ${ }^{20}$. But in Bangladesh, religious barrier regarding initiation is nil among Muslims.

Education of parents was found to have insignificant influence on CF practices except on frequency. This might be due to other influencing factors which are stronger than education e.g. advice of family members/ relatives/neighbors. But Bangladesh Demographic and Health Survey (BDHS) preliminary report (2007) showed that timely initiation of CF was more common in educated mothers than the mothers who were not educated or had primary level education. Maternal education level $(\mathrm{OR}=2.44,95 \% \mathrm{CI}: 1.42-4.19, \mathrm{p}<0.05)$ were found to be correlated to inappropriate feeding practices in China 21. Educated mothers in Uganda were more likely to prepare special complementary foods than the uneducated (OR= 2.7, CI 1.1-6.2) ${ }^{22}$. There was statistically significant difference observed in CF practices among educated and uneducated mother in Pakistan, but father's education did not have any correlation with infant feeding practices ${ }^{23}$.

Pre-lacteal feeding had significant influence on age of initiation and type of first complementary food. Prelacteal feeding is usually influenced by elderly members 
of the family (e.g. mother-in-law), relatives and neighbors. They also have great role for CF practices in our society. So, mothers are easily misguided by them.

Bottle feeding had significant influence on initiation, type of first complementary food and current main complementary food. Bottle feeding is easy for baby. So, once they are fed with bottle, they do not want to suck breast or take complementary foods. Bottle-fed babies had significantly delayed weaning (> 9 months) in Pakistan ${ }^{24}$.

Commercial cereal feeding has been increasing day by day even in low income group in our country. This food is not recommended here. It had been found to influence type of first complementary food and frequency of CF in this study. Frequency was more with commercial cereal as it is tasty, flavored and easily accepted by babies. Similar finding was found in a study by Lindsay et al. ${ }^{7}$.

Fast foods had been found to influence significantly the type of first complementary food, current main complementary food and it's frequency. These foods are also tasty, easily cooked, easily available and gladly accepted by children which deviates them from normal family foods. Heinig et al. also observed similar finding ${ }^{4}$.

Feeding during sleep at night is a common practice in our country. Usually formula/animal milk with or without rice gruel/suji are given to babies. This practice interferes with feeding of normal family foods. It had significant role on CF practices in this study, especially on current main complementary food and frequency. It is a common problem (82.6\%) in Sri Lanka too ${ }^{25}$.

Family support is very important for appropriate CF practices which are not sufficient in our country. Mothers are easily misdirected by family members. Lack of adequate knowledge and misconceptions among elderly persons, especially mother-in-law, who generally influences and guides child feeding practices in the family, are often important barriers. It affected initiation, type of first complementary food and current main complementary food in this study. Similar findings were observed by an Indian study ${ }^{14}$.

Mothers/caregivers' attitude towards CF practices can also influence a lot. Some are inherently reluctant and frequently influenced by other persons. 15.3\% were reluctant to feed their children appropriately in this study. Their negative attitude affected current main complementary food and frequency significantly.

Surprisingly, nutrition education of mothers/caregivers influenced significantly only the type of first complementary food in this study. This might be due to inadequate and ineffective methods of nutrition education in our country. But in a number of studies abroad, it has important role ${ }^{3,4}$.

\section{Conclusion:}

CF practices are still far from ideal in Bangladesh. Many factors affect different aspects of CF. Many persons around the mothers/caregivers influence them a lot. Educational qualification of parents has little positive role. Early and late initiations are due to some misconceptions. Bottle feeding, fast foods and lack of proper family support are the most important barriers of appropriate CF practices followed by pre-lacteal feeding, formula feeding, commercial cereal, feeding during sleep and negative attitude of mothers/caregivers.

\section{Recommendation:}

Pre-lacteal feeding and bottle feeding should be rooted out. Feeding of commercial cereal and fast foods, feeding during sleep should be discouraged. Family support is to be strengthened by improving nutrition education to family members, especially mother-in-law and husband. Attitude of mothers/caregivers must be changed by repeated counseling starting from antenatal visits. Whole community should be motivated and involved actively. Government organizations and NGOs along with mass media should be utilized more vigorously for awareness building.

\section{Acknowledgements:}

We are grateful to Swedish International Development Cooperation Agency (Sida), Sweden for support to conduct the study as a part of the training program on 'Child survival - Reaching the Target' and Prof. LarsAke Persson, Department of Women's and Children's Health, Uppsala University, Sweden for his continuous supervision \& guidance during the study.

\section{References}

1. World Health Organization. Nutrition: Complementary feeding, 2014.

2. Owino V O, Amadi B, Sinkala M, Filteau S, Tomkins A. Complementary feeding practices and nutrient intake from habitual complementary foods of infants and children aged 6-18 months old in Lusaka, Zambia (report). African 
Journal of food, Agriculture, Nutrition and Development. March 1, 2008.

3. Shi L, Zhang J, Wang Y, Caulfield LE, Guyer B. Effectiveness of an educational intervention on complementary feeding practices and growth in rural China: a cluster randomized controlled trial. Public Health Nutr. 2010 April; 13(4): 556-65. Epub 2009 Aug 26.

4. Heinig Jane, Follett Jennifer, Ishii Kara, KavanaghProchaska Katherine, Cohen Roberta, Panchula Jeanette. Barriers to compliance with infant-feeding recommendations among low-income women. Journal of Human Lactation. 22(1),2006.

5. USAID. Improving complementary feeding practices: A review of evidence from South Asia : Evidence review series 2 ; March 2008.

6. Alive \& thrive. Complementary feeding practices, 2009.

7. Lindsay AC, Machado MT, Sussner KM, Hardwick CK, Peterson KE. Infant-feeding practices and beliefs about complementary feeding among low-income Brazilian mothers: a qualitative study. Food Nutr Bull. 2008 Mar; 29 (1): 15-24.

8. Tamanna Begum, SK Azimul Hoque, Md. Rafiqul Islam, Soofia Khatoon, Azanta Rani Shah. Infant feeding practice of mother attending pediatric out patients department in a tertiary care center. Bangladesh J Child Health 2013; 37 (3): 138-141.

9. M Z Islam, S Farjana, J H B Masud. Complementary feeding practices among the mothers of a rural community. Northern International Medical College Journal 2012 Jan; 3(2): 204-207.

10. Akhtar K, Hoque ME, Islam MZ, Yusuf MA, Sharif AR, Ahsan AI. Feeding Pattern and Nutritional Status of Under Two Years Slum Children. J Shaheed Suhrawardy Med Coll. 2012; 4(1): 3-6.

11. Mahejabin F, Khan AW, Sultana M. Socio-demographic characteristics of the mothers and infant feeding practices in some semi urban villages of a selected upazilla.CBMJ 2013 Jan; 2 (1): 43-48.

12. Haque MJ, Rahman MM, Sarker SK, Ali MA, Fakir M, Rahman MM, Islam MM. Infant Feeding Practice by the Rural Mothers of Dinajpur District. Dinajpur Med Col J 2010 Jan; 3(1): 35-38.
13. WHO. Complementary feeding: Family foods for breastfed children. Geneva: World Health Organization. WHO/NHD/ 00.1: WHO/FCH /CAH/00.6; 2000.

14. Kumudha A, Khan ME, Hazra A. Increasing appropriate complementary feeding in rural Uttar Pradesh. The Journal of Family Welfare 2010; 56: 51-56.

15. Ruel MT, Brown KH, Caulfield LE. Moving forward with complementary feeding: indicators and research priorities. Food Consumption and Nutrition Division Discussion Paper 2003. Washington DC: International Food Policy Ins $146,1$.

16. Giasuddin MS, Kabir M. Duration of breast feeding in Bangladesh. Indian J Med Res 2004; 119: 267-272.

17. Zulkifli A, Kyi DW, Rahman AI. Breast feeding and weaning practices in rural communities of Kelantan, Malaysia. Mal J Nutr 1996; 2: 148-154.

18. Patrice LE. Infant feeding styles: Barriers and opportunities for good nutrition in India. Nutrition Reviews 2002; 60: 109-114.

19. Shembesh NM, Naseb N, Balo M, Singh R. Breast feeding and weaning patterns in Benghazi, Libyan Arab Jamahiriya. East Meditrn J Health 1997; 3(2): 251-257.

20. Bhardwaj N, Hasan BS, Zaheer M. feeding and weaning practices- A rural study in Uttar Pradesh. J Family Welfare 1991; 39(1): 23-29.

21. Li L, Li S, Ali M, Ushijima H. Feeding practice of infants and their correlates in urban areas of Beijing, China. Pediatr Int. 2003 Aug; 45(4): 400-6.

22. Wamani H, Astrøm AN, Peterson S, Tylleskär T, Tumwine JK. Infant and young child feeding in western Uganda: knowledge, practices and socio-economic correlates. J Trop Pediatr 2005 Dec; 51(6):356-61.

23. Memon S, Shaikh S, Kousar T, Memon Y, Rubina. Assessment of infant feeding practices at a tertiary care hospital. J Pak Med Assoc 2010; 71(12):1010-5.

24. Chaudhry R, Humayum N. Weaning practices and their determinants among mothers of infants. Biomedica 2007; 23(2): 120-124.

25. Priyantha J P, Meranthi F, Tania W, Nayomi R. Feeding practices among children attending child welfare clinics in Ragama MOH area: a descriptive cross-sectional study. International Breastfeeding Journal 2011; 6:18. 